competence can best be assessed. One descriptive account of assessment recommends full psychiatric evaluation, comprehensive observations of the mothers with their infants, and interviews with relatives to estimate future support. ${ }^{13}$ Although this commonsense approach is probably used in most mother and baby units, including those that now admit mothers with chronic illness for preliminary assessment and subsequent training in mothering skills, the practice is open to criticism. To be clinically useful, observations must be simple enough to be made by multiple carers on a psychiatric ward; excessive simplicity, however, may undermine their value. Also in doubt is their predictive validity, as no study has determined mother-infant interaction after discharge from a mother and baby unit or identified which observations during the admission are most crucial to prognosis.

A potential problem now exists in deciding who should pay for such detailed assessments: mother and baby units must attract referrals from outside their district to remain financially viable, and their high ratio of staff to patients is expensive. Health authorities will be asked to purchase this form of care, and social services will be required to pay directly for the advice they need. If they do not decisions may be made without the benefit of comprehensive observations and specialist experience. Some children may be removed prematurely from their families while others may be entrusted to incapable mothers whose difficulties remain undetected and untreated.

LOUIS APPLEBY Senior Lecturer CHRIS DICKENS Registrar

Department of Psychiatry,

Withington Hospital,

Manchester M20 8LR

1 Rutter M, Quinton D. Parental psychiatric disorder: effects on children. Psychol Med 1984;14:853

2 d'Orban PT. Women who kill their children. Br F Psychiatry 1979;134:560-71.

Rutter M. Family and school influences on cognitive development. $\mathcal{f}$ Child Psychol Psychiatr 1985;26:683-704.

Rodnick EH, Goldstein MJ. Premorbid adjustment and the recovery of mothering function in acute schizophrenic women. $f$ Abnorm Psychol 1974;83:623-8.

5 Blehar MC, Lieberman AF, Ainsworth MDS. Early face-to-face interaction and its relation to late infant-mother interaction. Child Dev 1977;48:182-94.

6 Pastor DL. The quality of mother-infant attachment and its relation to toddlers' initial sociability with peers. Developmental Psychology 1981;17:326-335.

Matas L, Arend RA, Sroufe LA. Continuity of adaption in the second year: the relationship between quality of attachment and later competence. Child Dev 1978;49:547-56. between quality of attachment and later competence. Child Dev 1978;49:547-56.

9 Accardo PJ, Whitman BY. Children of mentally retarded parents. Am f Dis Child 1990;144: $69-70$.

10 Cogill K, Caplan HL, Alexandra H, Robson KM, Kumar R. Impact of maternal postnatal depression on cognitive development of young children. $B M Y$ 1986;292:1165-7.

1 Caplan HK, Cogill SR, Alexandra H, Robson KM, Katz R, Kumar R. Maternal depression and the emotional development of the child. Br f Psychiatry 1989;154:818-22.

12 Wrate RM, Rooney AC, Thomas PF, Cox JL. Postnatal depression and child development. A three year follow-up study. Br f Psychiatry 1985;146:622-7.

13 Stewart D, Gangbar R. Psychiatric assessment of competency to care for the newborn. Can $f$ Psychiatry 1984;29:583-9.

\title{
Screening newborn infants for Duchenne muscular dystrophy
}

\section{Acceptable to parents}

Bradley and colleagues describe a programme for screening newborn infants for Duchenne muscular dystrophy on $\mathrm{p} 357 .{ }^{1}$ Symptoms of this severe $\mathrm{X}$ linked inherited disorder usually occur before the age of 6 , and the patient is bedridden by 12 and often dead by $20 .^{2}$

Newborn screening for genetic and other disorders is usually confined to diseases for which there is treatmenteither a change of diet (as in phenylketonuria and galactosaemia) or replacement therapy (as in hypothyroidism) - or in which there is a chance of affecting morbidity or mortality early in life, as occurs in the haemoglobinopathies (particularly sickle cell disease). Screening for disorders in which the clinical course cannot be altered is generally avoided: a programme of newborn screening for disorders like Duchenne muscular dystrophy could therefore create an ethical nightmare. Bradley and colleagues are well aware of these problems as they seek to justify newborn screening for this untreatable genetic disorder.

The authors argue that newborn screening for Duchenne muscular dystrophy decreases emotional distress because it avoids delays in diagnosing the disease, and without screening two or more boys could be born with the condition before parents realised that they were at risk of having an affected child. Accordingly, if an infant with Duchenne muscular dystrophy is identified early the family has the option of prenatal diagnosis for future pregnancies. On the other hand, neonatal diagnosis could interfere with normal emotional growth and the child's interaction with his family.

Data are presented from a programme throughout Wales, which began in July 1990 with several aims. These included giving families reproductive choice in future pregnancies, enabling them to plan for the future with a disabled child, avoiding the experience of a delayed diagnosis, and identifying a presymptomatic cohort who might benefit from future treatments. Parents were given the option of having their male infants screened for Duchenne muscular dystrophy in addition to the routine tests for phenylketonuria and congenital hypothyroidism. Informed consent was sought from parents, who were given an information sheet.

Blood was obtained by heel prick. Out of 16 cases that tested positive for creatine kinase, nine were confirmed, giving an incidence of 1:3082 births. Seven infants had a transient increase in creatine kinase activity; the authors say that no evidence exists that such rises are associated with the development of muscular dystrophy later in life. The refusal rate has varied between $5 \%$ and $6 \%$.

Considering the possibility of emotional trauma resulting from such a programme is crucial. Interestingly, only one of the nine families with an affected child had an above average level of emotional trauma. The other parents wanted to know about their son's condition early in life. Undoubtedly, the low incidence of emotional trauma was due in part to the careful protocol, which acknowledged that families risked finding out that their apparently healthy baby had a lethal disorder. Accordingly, the programme was designed so that it could be modified in the light of experience, and families could choose to discontinue investigation at every stage. Readers should pay particular attention to the careful, extensive community outreach organisation, which undoubtedly led to the minimal emotional impact of the programme.

University of Chicago,

JAMES E BOWMAN Professor of Pathology

Chicago, Illinois 60637, USA

\footnotetext{
Bradley DM, Parsons PE, Clarke AJ. Experience with screening newborns for Duchenne muscular dystrophy in Wales. $B M \mathcal{F}$ 1993:306:357-60.

McKusick VA. Mendelian inheritance in man: catalogs of autosomal dominant, autosomal recessive, and $X$-linked phenotypes. 10th ed. Baltimore: Johns Hopkins University Press, 1992:1916-26.
} 